\title{
Piaget como referencial teórico para o ensino e aprendizagem de adolescentes e adultos
}

Piaget as theoretical reference for the teaching and learning of adolescents and adults

\author{
Sérgio Choiti Yamazaki ${ }^{1}$ \\ Regiani Magalhães de Oliveira Yamazaki \\ Eliane Cerdas Labarce ${ }^{3}$
}

\section{Resumo}

Foram muitas as contribuições da epistemologia de Jean Piaget ao ensino de diversas áreas do conhecimento no decorrer das últimas décadas. As perspectivas interacionistas, críticas e progressistas que têm sido comumente adotadas, deram ao movimento construtivista um potencial interpretativo capaz de analisar os processos didático-pedagógicos por meio de superações de concepções individuais de senso comum. Apesar disso, por meio de nossa vivência em nossas atividades docentes cotidianas, levantamos a hipótese de que não é incomum a compreensão do aporte teórico piagetiano como uma referência teórica capaz de lidar somente com situações que envolvem eminentemente crianças e o início da adolescência. Os manuais didáticos que visam divulgar as contribuições piagetianas, apontam preponderantemente os conceitos e análises que se referem ou se enquadram à educação infantil, o que obstaculiza sua incorporação como referência teórica para investigações de situações que remetem ao Ensino Médio e ao Ensino Superior. Este trabalho trata-se de análises de uma pesquisa empírica feita com alunos de uma universidade pública do Brasil, que visou corroborar ou refutar nossa hipótese. Por fim, sugerimos para formação inicial ou continuada de professores, materiais que dizem respeito a pesquisas que se usam desta epistemologia a fim de estendê-la e de torná-la acessível para o docente em seu trabalho cotidiano.

Palavras-chave: epistemologia de Piaget; educação; didática; ensino médio; ensino superior.

\section{Abstract}

Jean Piaget's theory has given many contributions to the teaching of several areas of knowledge over the last decades. The interactionist, critical, and progressive perspectives that have been commonly adopted have given the constructivist movement an interpretive potential capable of analyzing the didactic-pedagogical processes by overcoming individual concepts of common sense. Despite this, through our experience in our daily teaching activities, we hypothesize that it is not uncommon to understand the Piagetian theoretical

\footnotetext{
${ }^{1}$ Universidade Estadual de Mato Grosso do Sul | sergioyamazaki@gmail.com

2 Universidade Federal da Grande Dourados | regianibio@gmail.com

3 Universidade Estadual de Mato Grosso do Sul | elianecerdas81@gmail.com
} 
contribution as a theoretical reference capable of dealing only with situations that eminently involve children and the beginning of adolescence. The textbooks that have the objective of disseminating Piagetian contributions mainly describe the concepts and analyzes that point to or are related to early childhood education, which hinders their introduction as a theoretical reference for investigations of situations that lead to High School and Higher Education. his paper makes an analysis of an empirical research done with students of a public university in Brazil that sought to confirm or refute our hypothesis. Finally, we suggest for initial teacher training or teacher training, materials that relate to research using this epistemology in order to extend it and make it accessible to the teacher in his daily work.

Keywords: epistemology of Piaget; education; high School; higher education.

\section{Introdução}

Por que estudar Piaget em pleno século XXI? Pesquisadores de distintas áreas podem nos mostrar o potencial teórico e prático da teoria piagetiana em responder às demandas sociais que procuram dar conta de problemas envolvendo o desenvolvimento humano, cognitivo, afetivo, ambiental. Para efeito de exemplificação, citamos um evento organizado pelo Grupo de Estudos de Psicologia e Epistemologia Genética e Educação, da UNESP: o Colóquio Internacional de Epistemologia e Psicologia Genéticas: atualidade da obra de Jean Piaget, realizado em 2011. Em sua apresentação, Montoya e Shimizu (2011) afirmam:

No que se refere à pesquisa, verificamos resultados vigorosos de trabalhos de grupos de pesquisa que, levando a sério a obra de Piaget, mostram novos fatos e novas interpretações. Assim, contrariamente à visão dos seus críticos, a obra de Piaget se mostra consistente e forte, capaz de promover profundas transformações teóricas e práticas. Basta constatar pesquisas inovadoras em campos pouco conhecidos até hoje, como dos valores morais, os conhecimentos culturais e sociais, os jogos e símbolos, as reflexões sobre a natureza e cultura, sobre natureza e sociedade e sobre ciência e filosofia etc. Desse modo, pode-se observar que, naqueles campos antigamente apontados como um dos pontos fracos da teoria de Piaget, pesquisas recentes mostram o seu potencial teórico e prático. É como se as viagens às Índias tivessem descoberto a América. (MONTOYA, SHIMIZU, 2011, p.i)

Complementando estes autores, Ramozzi-Chiarottino (2011) argumenta que:

Falar da atualidade da teoria de Jean Piaget é falar sobre suas concepções a respeito das "trocas" do organismo com o meio. Por "trocas com o meio", entenda-se desde aquelas que se operam na digestão dos alimentos até as trocas simbólicas das grandes realizações humanas, dentre elas as das várias linguagens que o homem criou no decorrer de sua história filogenética até a história ontogenética de cada um.

O aporte teórico elaborado por Piaget nas primeiras décadas do século XX influenciou muitos pesquisadores do campo da Educação e contribuiu com diversas linhas de pesquisa até os dias atuais. Ele nos deixou uma obra vasta sobre a origem e o desenvolvimento do 
conhecimento, fundando sua epistemologia genética através da qual pretendia responder à pergunta: como o conhecimento (ou o conhecimento científico) é possível? (BECKER, 2017). Responder a esta pergunta não era fácil em um tempo em que Piaget teve que lutar "contra as instituições e os preconceitos intelectuais de sua época" (MUNARI, 2010, p.12), que poderiam incluir os de fundo espiritualista e idealista, "para defender e promover o enfoque científico" 4 .

Assim, a extensa obra de Piaget inclui pesquisas nos mais variados campos, tais como Biologia, Filosofia, Psicologia, Lógica, Sociologia, Teologia, História, Física e Matemática (RAPPAPORT, FIORI, DAVIS, 1981, p.51). Porém, sua preocupação central girava em torno da compreensão dos processos de pensamento dos seres humanos, considerados sujeitos epistêmicos ${ }^{5}$. Piaget apresenta uma compreensão de que a construção do conhecimento acontece por meio da interação entre o meio (objetos) e os indivíduos (sujeitos), através da qual as adaptações ocorrem. Neste sentido, o progresso dos indivíduos se dá na medida em que eles se adaptam ao se deparar com distintos cenários - ambientes físicos e sociais "que rompem o estado de equilíbrio do organismo" (RAPPAPORT, FIORI, DAVIS, 1981, p.56) -, por um processo que ele chamou de assimilação e acomodação.

A assimilação refere-se aos fenômenos em que os indivíduos incorporam determinados elementos que dão conta de resolver algumas situações vivenciadas. Rappaport, Fiori e Davis (1981) citam como exemplo as seguintes vivências: "a partir [do momento] em que uma criança aprende a subir escadas, saberá fazê-lo em qualquer circunstância. O mesmo exemplo vale para aquisição de outros comportamentos motores, como correr, andar de bicicleta, chutar bola, varrer a casa etc." (p.57). Mas estas não se restringem a comportamentos físicos e, portanto, os autores também exemplificam o processo de assimilação por meio de outra situação: "... se a criança passou a dominar as quatro operações aritméticas básicas (somar, subtrair, multiplicar, dividir) saberá fazê-lo, sempre que solicitada" (p.57).

Os mecanismos mentais e/ou físicos incorporados pelos indivíduos, no entanto, muitas vezes se deparam com situações semelhantes que promoveram assimilação, mas que não podem ser resolvidos pelos mesmos mecanismos apreendidos (assimilados). Ocorre que neste momento, os indivíduos podem tentar resolver os novos problemas utilizando-se de outras ações, levando em consideração as especificidades que não existiam até então. Este processo faz com que a estrutura mental existente seja modificada tendo como fim o domínio da nova situação. Este processo de modificação de estruturas antigas com o objetivo de resolver novos problemas denomina-se acomodação.

Rappaport, Fiori e Davis (1981) afirmam que "os processos de assimilação e acomodação são complementares e acham-se presentes durante toda a vida do indivíduo" (p.58), os quais permitem que os organismos se adaptem a novas situações pela busca de constante equilíbrio biológico e mental com o meio.

Para Piaget (1970), o desenvolvimento não acontece de forma linear, mas através de saltos e rupturas que delimitam estágios de desenvolvimento, os quais ele estabeleceu empiricamente e denominou como sensório-motor, pré-operatório, operatório-concreto e

\footnotetext{
${ }^{4}$ Ibid., p.12.

5 Ibid., p.51.
} 
operatório formal. Cada um desses estágios representa uma lógica das estruturas mentais que será superada por um estágio superior que apresenta outra lógica do conhecimento.

O primeiro destes estágios, sensório-motor, transcorre no âmbito da motricidade e representa a forma de pensamento das crianças de zero a dois anos.

É o período da "inteligência prática" porque é uma fase do desenvolvimento cognitivo onde a criança não usa a linguagem, emprega apenas as suas ações e percepções, daí a razão da denominação desse primeiro estágio, pois é a ação e a percepção que estimulam o desenvolvimento das estruturas mentais. (PÁDUA, 2009, p 29)

O segundo estágio, transcorre na atividade representativa e é chamado de préoperatório. Por volta dos dois anos de idade a qualidade da inteligência se modifica e, ao contrário do primeiro estágio onde agir e saber eram uma realidade só, na transição para o segundo eles se separam e dá-se o início do "pensamento com linguagem, o jogo simbólico, a imitação diferenciada, a imagem mental e as outras formas de função simbólica". A criança permanece nesse estágio por cerca de cinco anos (PIAGET, 1971, p.104)

No terceiro estágio que ocorre por volta dos sete ou oito anos de idade, aproximadamente, depois de ter passado por algumas fases de transição, a criança chega à constituição de uma lógica e de estruturas operatórias denominadas concretas. Nestas, a criança faz uso da capacidade das operações reversíveis apenas em cima de objetos que ela pode manipular, de situações que ela pode vivenciar ou lembrar. Ainda não existe, por assim dizer, a abstração (PÁDUA, 2009).

O quarto e último estágio, operatório-formal, se refere à forma de pensamento que se faz possível por volta dos onze ou doze anos de idade. Ele indica que as pessoas, a partir deste estágio, avançam mais e mais em direção a raciocínios formais e abstratos (PÁDUA, 2009).

Por meio da caracterização desses estágios, Piaget mostra que existe uma sequência e uma sucessão no desenvolvimento da inteligência e que esse desenvolvimento passa, necessariamente, por cada um destes estágios.

Muitas investigações foram e estão sendo feitas (por exemplo, Carvalho, 1983; Becker, 2012) trazendo como aporte teórico as contribuições piagetianas para fundamentação de dados de pesquisa, mostrando o potencial interpretativo que elas podem oferecer. Estas são encontradas em demasia nos veículos científicos da área, tais como as revistas, os anais de eventos científicos e os textos didáticos produzidos no meio acadêmico.

Contudo, os artigos que trazem a referência teórica piagetiana para fundamentar os dados de pesquisa, seja esta teórica ou empírica, o fazem por meio de situações em que preponderantemente estão envolvidas as crianças. Embora seja possível encontrar pesquisas que procuram contemplar os adultos, os adolescentes ou jovens, estas são quantitativamente menores quando comparadas com as que têm a criança como sujeito da pesquisa. $O$ saber piagetiano poderia, por exemplo, explicar casos em que alunos ou professores preferem ou se satisfazem com vivências que se limitam a casos práticos, em uma versão utilitarista do emprego teórico em curso. É o caso da pesquisa de Merazzi e Oaigen (2007) que, analisando os dados da pesquisa perceberam "que a utilização de atividades práticas no ensino de 
Ciências na EJA é uma estratégia satisfatória no processo de ensino e aprendizagem"6 (MERAZZI, OAIGEN, 2007, p.1).

Artigos de Piaget também citam as crianças em suas análises, não fazendo (ou fazendo poucas) referências a idades mais avançadas dos indivíduos sujeitos da pesquisa. Por exemplo, no artigo "Desenvolvimento e Aprendizagem", texto de Piaget de 1964, traduzido para o português em 2009, é possível encontrar a palavra "criança" 41 vezes no decorrer do trabalho, enquanto as palavras "indivíduo", "jovem" (ou "jovens") e "adolescente" não são encontradas. A palavra "adulto" é encontrada uma única vez, mas não como protagonista do processo que se está avaliando. Ela é apresentada no seguinte recorte: "... a criança pode receber valiosa informação via linguagem, ou via educação dirigida por um adulto..." (PIAGET, 2009, p.4). Já a palavra "sujeito" é encontrada 10 vezes, mas deve-se tomar o seguinte cuidado com este dado, pois esta palavra se refere muitas vezes (talvez na maioria das vezes) ao contexto epistemológico, especialmente à gênese do conhecimento, em que distintas perspectivas são discutidas: empirista, racionalista (ou apriorista) e interacionista.

Para Pádua (2009), Piaget ganhou notoriedade como psicólogo infantil, mas sua preocupação era o entendimento da capacidade e do desenvolvimento do conhecimento humano. E como, na sua visão, a criança é o ser que mais notoriamente constrói conhecimento, suas pesquisas e observações voltaram-se para a construção e aquisição de conhecimento pelos homens na idade infantil e na adolescência.

Assim, os livros de Piaget trazem em muitos de seus títulos a palavra "criança" (PIAGET, 1999; PIAGET, 1994; PIAGET, 1990; PIAGET, 1986; PIAGET, 1985; PIAGET, 1975a; PIAGET, 1975b; PIAGET, 1975c; PIAGET, 1972; PIAGET, 1971; PIAGET, 1967; PIAGET, 1946; PIAGET, INHELDER, 1993a; PIAGET, INHELDER 1993b; PIAGET, INHELDER, 1977; PIAGET, INHELDER, 1951), o que pode estar levando a construção de representações sociais (MOSCOVICl, 2007) que obstaculizam a consideração desta epistemologia para análises e contribuições em se tratando da educação de adultos e quem sabe, até de adolescentes, uma vez que estes se encontram na perspectiva piagetiana, na fase formal, muitas vezes considerada como a fase em que os indivíduos já alcançaram os pressupostos cognitivos mais abstratos e avançados do ponto de vista psíquico estrutural.

Afinal, o livro ou manual de ensino é, apesar dos avanços didáticos "um condutor do currículo e das pedagógicas nas escolas" (...) [influenciando] largamente as aulas (...), seja sob a forma de atualização, estruturação (...) ou guia dos estudantes na compreensão do um mundo exterior" (SOUZA, VIEIRA, MELO, 2016, p.102). Os autores também afirmam que:

Dentro desta perspectiva, entendemos que o livro didático constitui um condutor escrito de escolhas curriculares, sendo assim um roteiro oficial

\footnotetext{
${ }^{6}$ Nossa intenção, ao citar este artigo, não é de criticá-lo por utilizar-se de atividades práticas como ferramenta didática para o ensino de jovens e adultos, pois conhecemos os resultados de pesquisas que mostram o potencial didático e motivador que elas possuem. Nossa intenção é de argumentar que o referencial piagetiano pode explicar casos como o apresentado no trabalho citado, ao aproximar as tendências comportamentais dos alunos e professores do aporte teórico de Piaget, tais como a permanência e o avanço em fases operatórias intrínsecas a este autor. Por exemplo, uma questão poderia ser proposta: um indivíduo que se apresenta na fase operatória concreta, teria preferência ou se satisfaria com vivências experimentais que não dialogam com hipóteses prévias sobre os resultados?
} 
para a escola e professores. Portanto, considerando a importância dos professores introduzirem argumentação em sala de aula, é importante compreender como a argumentação é (ou não é) construída nos textos dos livros didáticos e sob quais alicerces essa construção se apresenta. (SOUZA, VIEIRA, MELO, 2016, p.102)

Tendo em vista esse cenário, nossa hipótese é que o referencial teórico piagetiano, apesar de ter o potencial no que se refere aos aspectos que envolvem o ensino e a aprendizagem, para todas as idades, é compreendido e empregado preponderantemente a casos em que as crianças são protagonistas do processo. Neste sentido, este trabalho tratou de investigar uma pequena parte de um universo de indivíduos que se encontram nos campos acadêmicos a caminho de uma formação profissional docente. São licenciandos do $4^{\circ}$ ano de um curso de ciências biológicas de uma universidade pública do país, que tinham algum conhecimento da obra piagetiana anteriormente, por meio de disciplinas ou de projetos. Procuramos avaliar, por meio de questionário do tipo likert, se para eles este referencial é mais adequado quando se tem em vista a educação infantil.

\section{Metodologia}

Para a coleta de dados utilizamos um questionário do tipo "escala likert". Trata-se de um instrumento elaborado para medir atitudes relacionadas ao grau de concordância a certas afirmações referentes ao objeto pesquisado. Ao responder à escala likert, deve-se assinalar uma entre 5 respostas: totalmente de acordo (equivale a 5 pontos); de acordo (equivale a 4 pontos); neutro (equivale a 3 pontos); em desacordo (equivale a 2 pontos); totalmente em desacordo (equivale a 1 ponto).

As respostas a este questionário serão avaliadas segundo a equação "RM $=\sum$ (fiVi) / (NA), onde fi é a frequência de cada resposta à questão, Vi é o valor do item supracitado (de 1 a 5 pontos) e NA é o número de alunos que responderam à questão" (YAMAZAKI, YAMAZAKI, 2017, p.45), sendo RM o ranking médio de pontos para cada questão.

"O indicativo do nível de concordância foi fornecido pelo seguinte critério: RM $\leq 1,4$ (totalmente em desacordo); 1,5 $\leq \mathrm{RM} \leq 2,4$ (em desacordo); $2,5 \leq \mathrm{RM} \leq 3,4$ (neutro); 3,5 $\leq$ $\mathrm{RM} \leq 4,4$ (de acordo); 4,5 $\leq \mathrm{RM} \leq 5,0$ (totalmente de acordo)" (YAMAZAKI, YAMAZAKI, 2017, p.45). Esse critério considera que os pontos de 1 a 5 se referem ao nível crescente de concordância, por sua vez apresentada pelo valor de Vi, presente na equação de RM.

O questionário foi aplicado em 15 alunos do $4^{\circ}$ ano de um Curso de Ciências Biológicas de uma universidade pública do país. As questões respondidas pelos licenciandos foram as seguintes:

1) As teorias de Ausubel e Vygotsky são adequadas para o professor de biologia porque se referem a alunos que estão normalmente em idade apropriada para o Ensino Médio (fase formal). Já Piaget seria mais adequado para o professor de ciências, pois no Ensino Fundamental os alunos estão em sua maior parte na fase concreta (ou seja, menos do que 12 anos). 
2) No ensino de ciências, há teóricos que lidam somente com crianças e com fases iniciais da adolescência, como Piaget, e outros que lidam com adultos, como Ausubel e Vygotsky.

3) Piaget se mostra limitado para compreender o desenvolvimento intelectual de adultos. Para isso, precisamos de outro referencial teórico, como, por exemplo, a teoria de Vygotsky.

A primeira questão tem o objetivo de avaliar a compreensão de que o referencial piagetiano é mais apropriado para analisar situações em que os indivíduos ainda não alcançaram a idade atribuída à fase formal, ou seja, antes dos 12 anos. Contudo, a compreensão de que é "mais apropriado" não significa entender que o aporte teórico não possa ser utilizado para pesquisas envolvendo indivíduos de idades mais avançadas - após os 12 anos de idade. Com a intenção de complementar a questão 1, a questão 2 visa verificar se para os sujeitos da pesquisa o referencial piagetiano pode ser utilizado para interpretar somente dados envolvendo crianças. Considerando que as respostas dos alunos podem apontar para a negação da questão 2, de forma suplementar, a questão 3 tem o objetivo de apontar indícios, reforçando a questão 1, de que a teoria de Piaget apesar de poder ser utilizada para analisar fenômenos protagonizados por jovens e adultos, é mais apropriada para considerações de casos infantis, em que os indivíduos não ultrapassaram os 12 anos de idade, portanto, indo até a etapa denominada pelo autor como a fase concreta.

\section{Respostas ao Questionário - Escala Likert}

As respostas à primeira questão, em porcentagens são as seguintes: 40\% estão totalmente de acordo, 33,33\% estão de acordo e 26,67\% neutros. Significa que 73,33\% estão de acordo ou totalmente de acordo com a ideia de que o referencial piagetiano é mais adequado para interpretar situações envolvendo crianças. Utilizando a equação RM, o resultado é $\mathrm{RM}=4,13$ (de acordo).

A segunda questão é mais incisiva ao afirmar que Piaget lida "somente com crianças e com fases iniciais da adolescência", enquanto outros "lidam com adultos, como Ausubel e Vygotsky". O resultado aponta que 20\% estão totalmente de acordo, 26,67\% estão de acordo, 6,67\% neutros, 40\% estão em desacordo e 6,67\% estão totalmente em desacordo. Percebemos que as respostas estão distribuídas entre as várias alternativas possíveis. Ao aplicar a equação de $\mathrm{RM}$, que leva ao resultado final, vemos que RM = 3,13 (Neutro).

A terceira questão afirma que Piaget se mostra limitado para compreender 0 desenvolvimento de adultos. O resultado mostra que 13,33\% estão totalmente de acordo, $60 \%$ estão de acordo, 20\% neutros e 6,67\% estão em desacordo, com RM = 3,8 (de acordo).

Dessa forma, o cenário que parece mostrar os resultados é a seguinte: Piaget faz referência a casos envolvendo adolescentes e adultos, mas apresenta limitações para analisálos, havendo, portanto, necessidade de outro referencial mais apropriado para estas faixas etárias. 


\section{Pesquisas fundamentadas em Piaget: jovens e adultos como objetos de estudo?}

Os dados empíricos desta pesquisa apontam para compreensão de que a teoria piagetiana trata preponderantemente de questões protagonizadas por crianças, as quais podem estar compreendidas nas fases sensório-motor (0 a 2 anos), pré-operatórias (2 a 7 anos) e a concreta (7 a 11 anos). Embora Piaget apresente em sua teoria a fase formal, que compreende indivíduos com mais do que 11 anos de idade, o imaginário que corresponde ao senso comum pode estar enquadrando-o como aquele que lida com problemas inerentes aos períodos anteriores.

O enquadramento da teoria piagetiana a casos da infância, pode estar refletindo perspectivas originadas em divulgações dos mais diferentes tipos, desde as divulgações científicas até aquelas promovidas pelas mídias não especializadas (por exemplo, os jornais impressos e eletrônicos e os vídeos encontrados na internet).

Além disso, os próprios pesquisadores e professores podem estar trabalhando com a perspectiva preponderantemente infanto-juvenil, em sua maioria. Para verificar se esta hipótese tinha sentido, fizemos um levantamento de pesquisas publicadas no Encontro Nacional de Pesquisa em Educação Científica (ENPEC). Escolhemos este evento por ser o maior da área de Ensino de Ciências do país. Somente 2 artigos que se fundam em Piaget foram encontrados nos 4 últimos ENPECs (2017, 2015, 2013, 2011), sendo que um deles trata de divulgar uma estratégia de ensino, baseada em Piaget, para crianças de $1^{\mathrm{a}}$ a $4^{\mathrm{a}}$ séries; e 0 outro, ao apresentar um estudo das principias ideias de Piaget na literatura, relaciona-o ao estudo de crianças, não fazendo referência à educação de adolescentes e adultos.

Algumas considerações podem contribuir para esta análise. Como suposição, adolescentes e adultos se encontram na etapa piagetiana que corresponde à fase formal. Se esta é pouco pesquisada ou desenvolvida nos cursos universitários, a ideia de que Piaget trata principalmente de problemas relacionados às fases anteriores está de alguma forma implícita. Contudo, nem sempre as idades satisfazem às fases. É possível encontrar jovens e adultos em fases que comumente são atribuídas às crianças. Há pesquisas que mostram adultos na fase concreta (HERRON, 1975; GOOD; KROMHOUT; MELLON, 1979; GOODSTEIN, HOWE, 1978), o que significa que falham quando necessitam da fase formal (CHIAPPETTA, 1976). Analogamente, também as crianças parecem em alguns casos avançar além das fases relacionadas a suas idades, o que fez com que alguns autores afirmassem que Piaget subestimou as crianças (AUBREY, 1993; BAILLARGEON, 1991; GELMAN, MECK, MERKIN, 1986; SIEGAL, 1999).

Se tomadas com todo o rigor que merecem, estas pesquisas sugerem a necessidade de levantamentos empíricos a fim de verificar em que fase se encontram os aprendizes a fim de dar conta de planejamentos de ensino que de fato funcionem - ou seja, promovem aprendizagem. No entanto, o próprio Piaget (1972) atualiza seus resultados ao afirmar que as fases para as quais aponta são aproximadas, propondo caracterizá-las como um possível potencial a ser desenvolvido.

As estruturas intelectuais entre o nascimento e o período de 12-15 anos surgem lentamente, mas de acordo com os estágios do desenvolvimento. 
A ordem de sucessão desses estágios, como foi mostrado, é extremamente regular e comparável aos estágios de uma embriogênese. A velocidade do desenvolvimento, no entanto, pode variar de um a outro indivíduo e também de um a outro meio social; consequentemente podemos encontrar algumas crianças que avançam rapidamente e outras que avançam lentamente, mas isso não muda a ordem de sucessão dos estágios pelos quais passam. (PIAGET, 1972b)

Sua teorização diz respeito a adaptações realizadas pelos indivíduos por meio de assimilações e acomodações, as quais podem estar influenciando a fase em que se encontra o sujeito, esteja ele na etapa infanto-juvenil ou na fase adulta. Esta conclusão sugere que pesquisas e ensino podem ser desenvolvidos em todas as fases, o que já apontava a teoria piagetiana antes das críticas por ela enfrentadas; estas críticas vieram e reforçaram suas considerações para as situações protagonizadas por adultos ou adolescentes.

Embora em menor número, há pesquisas dentro desta perspectiva. Para efeito de exemplificação, nos atemos em uma delas, para refletir sobre seu potencial explicativo. Carvalho (1993) analisando a compreensão de conceitos da Química, ressalta que para realizar as operações intrínsecas a este conhecimento é necessário que o indivíduo esteja inserido no estágio formal piagetiano, pois do contrário, o aluno não entende o conteúdo ministrado. 0 desconhecimento desta possibilidade, em muitos casos, pode levar professores a não entender o que está por trás da incompreensão dos alunos, afinal, "é tão espontâneo em nós, professores de ciências, que nos espantamos (...) e não raro não conseguimos compreender o que eles não entendem" (CARVALHO, 1993, p.56).

A autora mostra em sua pesquisa que "os sujeitos de nível concreto [piagetiano] fazem uma leitura sistemática da experiência bruta, pois eles já classificam, seriam e fazem correspondência" (CARVALHO, 1993, p.58). No entanto, há certas limitações para compreensão dos fenômenos que estão representando ao constatar que "... essas são leituras e fatos apresentados à observação, e não provocados com o objetivo de verificar uma hipótese (...)" (CARVALHO, 1993, p.58), o que leva à seguinte conclusão: "Assim, quando o experimentador escolhe dois fatores para comparação, mantendo os outros constantes, a comparação feita (...) [pelo indivíduo] parece significativa, mas quando pede para ele resolver sozinho, tudo se complica (...)" (CARVALHO, 1993, p.58). Essa verificação induz a autora a afirmar que:

Os sujeitos do estágio de operações concretas, sabendo ler a experiência sob a forma de correspondências diversas (comprimento x peso, grossura $x$ comprimento etc.), podem construir implicitamente tabelas de duas entradas, mas não sabem interpretá-las, a não ser no caso de correspondência imediata, e não conseguem dissociar os fatores. (CARVALHO, 1993, p.58)

Como compreender estas dificuldades dos alunos quando não consideramos a fase na qual eles se encontram? Trata-se, pois, de um modelo explicativo com grande potencial analítico capaz de contribuir com ensino e aprendizagem e promover avanços didáticos reais. 
A pesquisadora mostra nesta investigação que a partir dos 15 ou 16 anos os alunos conseguem fazer operações relacionadas à fase formal, e apresenta dados que corroboram a inserção nesta fase: "Os sujeitos de nível formal 'começam a verificar os fatos, como no nível $\|^{7}$, por meio de operações concretas de classificação e correspondência' ${ }^{8}$, mas não param por aí, considerando essas operações como ponto de partida para novas operações" (CARVALHO, 1993, p.60). A análise remete à seguinte afirmação:

Vemos então o aparecimento de duas condutas, para nós, professores de Ciências, muito importantes e que não tinham significado para os alunos do nível concreto: o aparecimento da hipótese (...) e da prova sistemática, que nada mais é do que o estabelecimento das combinações que efetivamente obedecem à experiência, permanecendo "todas as outras iguais". Em outras palavras, o "sujeito de nível II aceita tudo em confusão e o de nível III só utiliza suas descrições concretas preliminares como matériaprima para hipóteses e provas"9. (CARVALHO, 1993, p.60, grifos em negrito são nossos)

Carvalho (1993) mostra dados que levam a compreensão de alguns alunos na fase formal os quais muitas vezes "não se contentam em apenas achar a solução do problema, mas procuram ver se existem outras soluções" (p.64), fazendo jus ao pensamento hipotéticodedutivo, que caracteriza a fase formal. Nesta fase, os indivíduos não mais se referem "à realidade percebida, mas a partir dessa realidade enuncia proposições hipotéticas" (p.65).

Uma das possíveis consequências do desconhecimento dos fatores apresentados, é o cometimento de equívocos e incompreensões em sala de aula com relação ao campo da didática, em especial, aos aspectos que levam à avaliação da aprendizagem. Essa possibilidade leva a pesquisadora à seguinte preocupação: "... quando nós avaliamos uma classe, temos de estar conscientes das limitações desses alunos. Não podemos reprovar pessoas só porque elas ainda não são capazes de raciocinar formalmente" (p.76). Ao contrário, como professores, um de nossos compromissos deve ser o de "apresentar situações que estimulem o aparecimento de raciocínio formal", uma vez que "o objetivo primordial da educação é o desenvolvimento do indivíduo" (p.76).

Além da pesquisa supracitada, que analisa o caso do ensino de Química, outras investigações tratam de analisar os elementos epistemológicos referentes à educação científica, em distintas áreas do conhecimento (por exemplo, Gomes e Bellini, 2009; Manzini, 2007, sobre Ensino de Física; Becker, 2012, sobre ensino de Matemática; e Cirino et al., 2009, sobre Ensino de Química). Dessa forma, embora em menor número (quando comparado com as pesquisas cujo foco é a educação infantil), estas aparecem relevantes para promover avanços em se tratando de uma Educação Científica que requer uma transformação significativa e duradoura (PIAGET, 1972).

\footnotetext{
7 "Nível II" trata-se do "Nível Concreto".

${ }^{8}$ A autora referencia este trecho como sendo de INHELDER, PIAGET, 1976, p.44.

${ }^{9}$ A autora novamente referencia a obra de INHELDER, PIAGET, 1976, p.42.
} 


\title{
Considerações finais
}

Gomes e Bellini (2009) apresentam uma questão sobre a relevância de conhecer (ou não) o referencial piagetiano, para o ensino de Física:

\begin{abstract}
Perguntamos se precisamos conhecer Piaget para sermos professores de Física. A resposta pode ser não se, para nós, não importa o tipo de ensino e de pergunta que podemos fazer sobre os conteúdos da ciência física que ensinamos. Mas, a resposta será sim, se nos preocupamos com a nossa conduta epistemológica em sala de aula. Se os conteúdos de física são vistos como produtos de atividades operatórias complexas de dedução e experimentação e se queremos ir além do empirismo e de um ensino puramente transmissor de conhecimentos, então a teoria piagetiana nos fornecerá argumentos sólidos para a ação docente cotidiana em situação de ensino de física. (GOMES, BELLINI, 2009, p.9)
\end{abstract}

A questão remete à reflexão sobre os objetivos do ensino e aprendizagem não somente da Física, mas de outros campos disciplinares das ciências. Se a formação não deve ir além da formação técnica que permite a reprodução de conteúdos, então talvez não precisemos de Piaget. Esta característica didática está presente em muitos livros textos, e constitui um universo a ser problematizado (YAMAZAKI, ANGOTTI, DELIZOICOV, 2017). Mas se consideramos a formação de sujeitos críticos e autônomos, conforme sugere os Parâmetros Curriculares Nacionais, então a referência piagetiana contribui para ela, em todos os níveis de ensino, do infanto-juvenil ao adulto.

Afinal, como afirma Lino de Macedo, que há décadas tem se debruçado sobre a obra piagetiana e suas aplicações, Piaget "é um epistemológo, que se preocupa em descrever os passos necessários à construção do conhecimento... e a escola uma instituição que procura introduzir (...) um 'saber sistematizado'" (MACEDO, 1987, p.71) para que o indivíduo supere seu "estado atual, de ignorância ou confusão" (MACEDO, 1987, p.71). Para ambos, escola e Piaget, a preocupação sobre o desenvolvimento intelectual dos indivíduos é central. O pesquisador chama a atenção para necessidade de transformação da obra de Piaget para a realidade escolar, mas que isto não pode ser feito a qualquer custo, sendo primordial a preservação dos princípios epistemológicos da teoria.

Segundo Becker (2017), "Piaget busca compreender como o ser humano aprende ou, melhor, como se desenvolve cognitivamente; isto é, como ele passa de um conhecimento mais simples a um mais complexo". "O que poderia ser mais difícil de conhecer do que conhecer o modo como conhecemos?" (DAMÁSIO, 2000, p.18 apud BECKER, 2017, p.14).

Apesar de hoje encontrarmos outras referências teóricas capazes de lidar com os problemas relacionados ao ensino e aprendizagem, os resultados das pesquisas de Piaget e sua elaboração teórica ainda são bastante atuais, em especial seu embasamento teórico de assimilação, acomodação e adaptação que podem se dar em todas as idades, permitindo explicar como os indivíduos progridem e auxiliando os profissionais da educação na construção e execução de atividades didaticamente significativas. 


\section{Referências}

AUBREY, Carol. An Investigation of the Mathematical Knowledge and Competencies which Young Children Bring into School. British Educational Research Journal, v.19, n.1, p.27-41, 1993.

BAILLARGEON, Renée. Reasoning about the height and location of a hidden object in 4.5 and 6.59month-old infants. Cognition, v.38, p.13-42, 1991.

BECKER, Fernando. Epistemologia do Professor de Matemática. Petrópolis, RJ: Editora Vozes, 2012.

BECKER, Fernando. Paulo Freire e Jean Piaget: teoria e prática. Revista Eletrônica de Psicologia e Epistemologia Genéticas, v.9, número especial, p.7-47, 2017.

BECKER, Fernando. Paulo Freire e Jean Piaget: teoria e prática. Schème - Revista Eletrônica de Psicologia e Epistemologia Genéticas, v.9, número especial, p.7-47, 2007.

CARVALHO, Anna Maria Pessoa de. Piaget e o Ensino de Ciências. Revista da Faculdade de Educação, v.9, n.1, p.55-77, 1983.

CHIAPPETTA, Eugene L. A Review of Piagetian Studies Relevant to Science Instruction at the Secondary and College Level. Science Education, v.60, n.2, p.253-261, 1976.

CIRINO, Marcelo Maia et al. A intermediação sobre a noção de Probabilidade na construção de conceitos relacionados à Cinética Química. Ciência \& Educação, v.15, n.1, p.189-219, 2009.

DAMÁSIO, António Rosa. O mistério da consciência: do corpo e das emoções ao conhecimento de si. São Paulo: Cia das Letras, 2000.

GELMAN, Rochel; MECK, Elizabeth; MERKIN, Susan. Young Children's Numerical Competence. Cognitive Development, v.1, p.I-29, 1986.

GOMES, Luciano Carvalhais; BELLINI, Luzia Marta. Uma revisão sobre aspectos fundamentais da teoria de Piaget: possíveis implicações para o ensino de física. Revista Brasileira de Ensino de Físıca, v.31, n.2, p.1-9, 2009.

GOOD, Ron; KROMHOUT, Robert A.; MELLON, E. K. Piaget's Work and Chemical Education. Journal of Chemical Education, v.56, n.7, p.426-430, 1979.

GOODSTEIN, Madeline P.; HOWE, Ann C. Application of Piagetian Theory to Introductory Chemistry Instruction. Journal of Chemical Education, v.55, n.3, p.171-173, 1978.

HERRON, J. Dudley. Piaget for Chemists: Explaining what "good" students cannot understand. Journal of Chemical Education, v.52, n.3, p.146-150, 1975.

INHELDER, Bärbel; PIAGET, Jean. Da Lógica da Criança à Lógica do Adolescente: ensaio sobre a construção das estruturas operatórias formais. São Paulo: Pioneira, 1976.

MACEDO, Lino de. Para uma aplicação pedagógica da obra de Piaget: algumas considerações. Cadernos de Pesquisa, v.61, p.68-71, 1987.

MANZINI, Neiva Irma Jost. Roteiro Pedagógico: um instrumento para a aprendizagem de conceitos de Física. Ciência \& Educação, v.13, n.1, p.127-138, 2007. 
MERAZZI, Denise Westphal; OAIGEN, Edson Roberto. Atividades Práticas do Cotidiano e o Ensino de Ciências na EJA: a percepção de educandos e docentes. Amazônia - Revista de Educação em Ciências e Matemática, v.3, n.5, p.1-18, 2006.

MONTOYA, Adrian Oscar Dongo; SHIMIZU, Alessandra de Morais. Apresentação. In: MONTOYA, Adrian Oscar Dongo et al. Jean Piaget no Século XXI: escritos de epistemologia e psicologia genéticas. São Paulo: Cultura Acadêmica Editora; Marília: Oficina Universitária, 2011. p.i-v.

MOSCOVICl, Serge. Representações sociais: investigações em psicologia social. $5^{a}$ ed. Petrópolis, RJ: Vozes, 2007.

PÁDUA, Gelson Luiz Daldegan. A Epistemologia Genética de Jean Piaget. Revista FACEV, n.2, p. 22-35, 10 Semestre de 2009.

PIAGET, Jean. Seis estudos de psicologia. Rio de Janeiro: Forense Universitária, 1971.

PIAGET, Jean. A Construção do Real na Criança. Rio de Janeiro: Zahar, 1975a.

PIAGET, Jean. A evolução intelectual da adolescência à vida adulta. Tradução de Tania Beatriz Iwaszko Marques e Fernando Becker. 1972. In: https://www.ufrgs.br/psicoeduc/piaget/daadolescencia-a-vida-adulta/. Acesso em 14 de setembro 2018.

PIAGET, Jean. A Formação do Símbolo na Criança. Rio de Janeiro: LTC, 1990.

PIAGET, Jean. A Gênese do Número na Criança. Rio de Janeiro: Zahar, 1975c.

PIAGET, Jean. A Linguagem e o Pensamento da Criança. $7^{a}$ edição. São Paulo: Martins Fontes, 1999.

PIAGET, Jean. A Noção de Tempo na Criança. Rio de Janeiro: Record Cultural, sem data. (Ed. Original, 1946).

PIAGET, Jean. A Práxis na Criança. Rio de Janeiro: Forense, 1972.

PIAGET, Jean. A Representação do Mundo na Criança. Rio de Janeiro: Record, 1975b.

PIAGET, Jean. Desenvolvimento e Aprendizagem. In: Desenvolvimento e Aprendizagem sob o Enfoque da Psicologia II, UFRGS - PEAD 2009/1. Traduzido do original incluído no livro de: LAVATTELLY, C. S. e STENDLER, F. Reading in child behavior and development. New York: Hartcourt Brace Janovich, 1972. Reimpressão de RIPPLE R. e ROCKCASTLE, V. Piaget rediscovered. Cornell University, 1964.

PIAGET, Jean. Development and learning. In: LAVATELLY, C. S. e STENDLER, F. Reading in child behavior and development. New York: Hartcourt Brace Janovich, 1972.

PIAGET, Jean. Epistemologia Genética. Petrópolis: Vozes, 1970.

PIAGET, Jean. O Desenvolvimento das Quantidades Fisicas na Criança: Conservação e atomismo. Rio de Janeiro: Zahar Editores, 1971.

PIAGET, Jean. O Juízo Moral na Criança. $4^{a}$ edição. São Paulo: Summus, 1994.

PIAGET, Jean. O Nascimento da Inteligência na Criança. Lisboa, Portugal, 1986. 
PIAGET, Jean. O Possível e o Necessário: evolução dos possíveis na criança. Porto Alegre: Artes Médicas, 1985.

PIAGET, Jean. O Raciocínio na Criança. Rio de Janeiro: Record, 1967.

PIAGET, Jean; INHELDER, Bärbel. A Imagem Mental na Criança. Rio de Janeiro: Livraria Civilização Editora, 1977.

PIAGET, Jean; INHELDER, Bärbel. A Origem da Ideia do Acaso na Criança. Rio de janeiro: Record, sem data. (Originalmente publicado em 1951).

PIAGET, Jean; INHELDER, Bärbel. A Psicologia da Criança. Lisboa, Portugal: Edições Asa, 1993a. PIAGET, Jean; INHELDER, Bärbel. A Representação do Espaço na Criança. Porto Alegre: Artes Médicas, 1993b.

RAMOZZI-CHIAROTTINO, Zelia. A Atualidade da Teoria de Jean Piaget: A Embriologia Mental e a Demonstração, nos EEUU, do RNA influindo sobre o DNA a partir das Agressões do Meio. In: MONTOYA, Adrian Oscar Dongo et al. Jean Piaget no Século XXI: escritos de epistemologia e psicologia genéticas. São Paulo: Cultura Acadêmica Editora; Marília: Oficina Universitária, 2011. P.1-13.

RAPPAPORT, Clara Regina; FIORI, Wagner da Rocha; DAVIS, Cláudia. Psicologia do desenvolvimento: Conceitos fundamentais. v.1. São Paulo: EPU, 1981.

SIEGAL, Michael. Language and thought: the fundamental significance of conversational awareness for cognitive development. Developmental Science, v.2, n.1, p.1-34, 1999.

SOUZA, André Henrique Silva; VIEIRA, Rodrigo Drumond; MELO, Viviane Florentino. Atividades argumentativas em livros didáticos de Física do PNLD 2015: o incentivo ainda é escasso. Amazônia - Revista de Educação em Ciências e Matemática, v.13, n.25, p.100-115, 2016.

YAMAZAKI, Sérgio Choiti; ANGOTTI, José André Peres; DELIZOICOV, Demétrio. Aprender como ensinar física através do livro texto de ciclo básico universitário: um fenômeno didático em questão. Amazônia - Revista de Educação em Ciências e Matemática, v.13, n.28, p.5-22, 2017.

YAMAZAKI, Sérgio Choiti; YAMAZAKI, Regiani Magalhães de Oliveira. Experimentos no Ensino de Física: um olhar de viés epistemológico. Revista Exitus, v.7, n.3, p.38-63, 2017. 